\title{
Skin care in the aging female: myths and truths
}

\author{
Ushma S. Neill \\ Journal of Clinical Investigation, Ann Arbor, Michigan, USA.
}

\begin{abstract}
I recently had the opportunity to visit a very relaxing and beautiful day spa during the middle-of-the-day break from the sessions at a Keystone meeting. I was having a very tranquil and restorative day, when I went in for my final treatment - $\mathbf{a}$ facial. The very chipper and cheerful esthetician began examining my skin and applying various creams, when I then heard her say something that nearly ruined my experience: she claimed that the topical treatment she was about to apply would, in her words, "cleanse my liver."
\end{abstract}

As a scientist, I know better. The bulk of the over-the-counter potions that day spas use are harmless and are meant to cleanse the skin and increase transient moisture retention, and to cleanse anything more than my skin seemed a mighty claim. So I decided to embark on a difficult assignment for the sake of the JCI readership: to determine whether a facial or other topical treatments are worthwhile investments to keep skin healthy and wrinkle free. And to see whether or not it is even possible for a topical treatment to cleanse the liver. In pursuit of this goal, I spoke with four dermatologists (Figure 1) and two estheticians. Here are their perspectives on how to keep your skin (and liver) in the best state possible.

\section{The estheticians' point of view}

Given that the skin is our largest organ and certainly the most visible one, most of us would agree that taking care of it properly is important. In fact, the skin-care industry estimated Americans alone spend over $\$ 43$ billion per year (1) on topical creams, cosmetic enhancements such as Botox, and spa treatments (spending in this industry alone is over $\$ 12$ billion; ref. 2).

To find out more about facials, I spoke with two estheticians (neither of whom wanted to be named for this article) at spas in New York City. I also spent some time reading esthetician blogs and other skin-care articles on the Internet. According to the estheticians consulted, a professional facial usually includes some variation on these steps: a thorough cleansing of the skin; a skin analysis by the facialist; exfoliation; extraction of blackheads, clogged pores, and pimples if necessary; a facial massage; a treatment mask; and the application of serums, moisturizers, and sunscreens. Sometimes the facial includes a hand and arm massage, all in the pursuit of both healthier skin and relaxation. In order to preserve youthful skin (in women), they advised quarterly facials, beginning around the age of 25 .

One facialist I spoke to said that by getting a proper analysis of your skin, you will learn your skin type so as to properly address your skin's needs. She claimed that most people are using the wrong products for their skin type and that this causes the skin to become sensitized. Online, I found an esthetician blog that was quite emphatic about how a facialist is better placed than most to recommend topical products and treatments, stating "estheticians have available to them a wide variety of skin-care products that are professional-only products and estheticians know how to use these products properly. Without the training and knowledge of a licensed esthetician, finding the right products for your skin can

Conflict of interest: The author has declared that no conflict of interest exists. Citation for this article: J Clin Invest. 2012;122(2):473-477. doi:10.1172/JCI61978. just be a downright futile endeavor" (3). This is a message I can certainly agree with - the cosmetics sections of most department stores or even most drugstores have a dizzying array of options, and the marketing and packaging can seduce even the most logical of scientists. Splurging on the fancy packaging and boutique skin care can feel wonderfully indulgent, which in and of itself can have psychological benefits.

This is a point the estheticians came back to again and again the psychological impact a facial can have. They claimed that the relaxing effect of the facial does nothing but benefit your skin and your overall mental and physical health. One claimed, "The stress of daily life shows up in your skin, so taking an hour to relax and focus on yourself will help you physically and emotionally. Sure, facials are a luxury because of the money and time spent, but think about the fact that you have over an hour of protected time without your cell phone ringing and your e-mail buzzing. There is no way to underestimate the power of a little rest, relaxation, and rejuvenation."

So just how much can relaxation do from a scientific point of view? In my experience, much of the relaxation comes from the massage component of a facial. Again, from the blog, "Massage is a big part of a professional facial. Massage will help you to relax and will also reduce the stress hormone cortisol in your body. If cortisol is left to run amok in the body, it will only hurt you over time, and additionally, massage releases oxytocin, which is one of the body's feel-good hormones" (3). Unfortunately, the point about cortisol is not completely true - a recent study showed that massage therapy's effect on cortisol is "generally very small and, in most cases, not statistically distinguishable from zero" (4). Nor is the point about oxytocin completely accurate: two studies point to near minimal changes in oxytocin as a result of tactile stimulation $(5,6)$.

The estheticians I spoke to and blogs I read went on to discuss other medical benefits to facials: regulation of the immune system, detoxification, reduction in fluid buildup, exfoliation, and lymphatic drainage. Antioxidant facials were claimed to contain free-radical-fighting nutrients that would help remove pollutants from the body (perhaps cleansing my liver?). High frequency electrical currents were also touted as being effective as part of a facial, with claims that they would enhance blood circulation, increase collagen and elastin production, eliminate toxins and bacteria, encourage lymphatic drainage, exfoliate dead skin cells, and improve skin-care product absorption. I approached the bulk of these claims with suspicion.

\section{The dermatologists' point of view}

Given my hesitation about the medical benefits of topical skin treatments, I approached four dermatologists - three academic derma- 

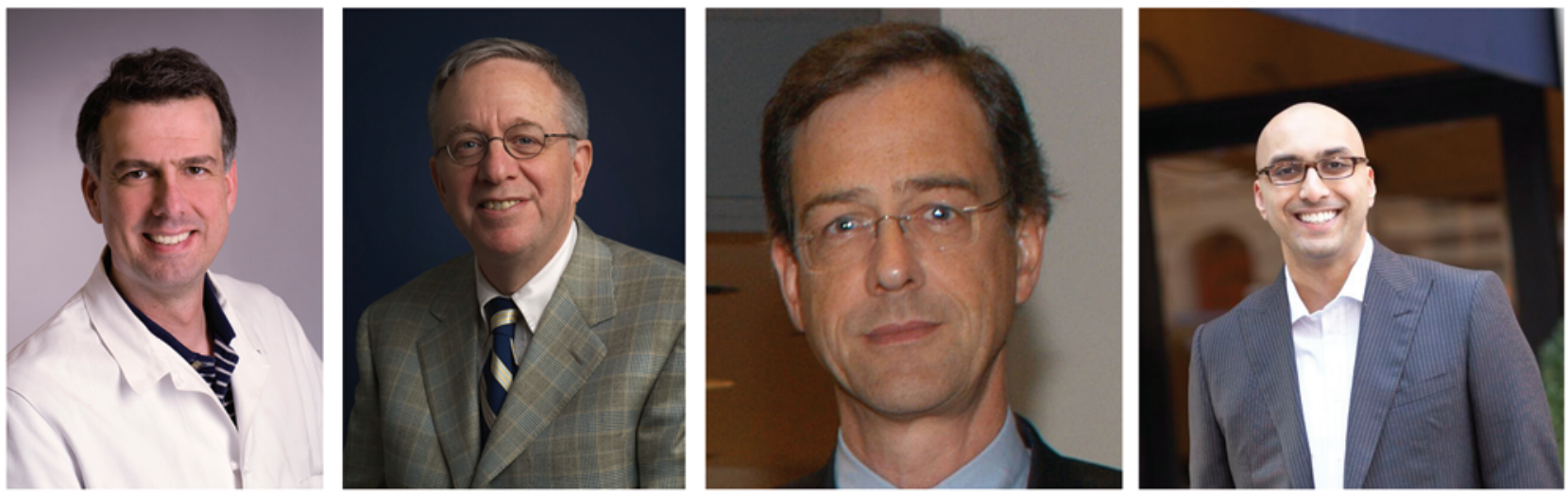

Figure 1

The consulting dermatologists, left to right: George Cotsarelis, John R. Stanley, Michael Detmar, and Adarsh Mudgil.

tologists (George Cotsarelis, John R. Stanley, and Michael Detmar) and one Fifth Avenue clinician (Adarsh Mudgil) in my neighborhood to answer some questions about facials and skin care.

We began with a quick primer on skin: just how deeply could a topically applied product available from a spa penetrate the skin (Figure 2)? Apparently, a typical ingredient in an effective skincare product can break up the dead stratum corneum cells and can cause a reactive proliferation of the basal keratinocytes, but most creams do not penetrate through the epidermis. Something like a protein won't go anywhere past the surface. All the dermatologists spoke at length about retinoids, a class of chemical compounds that are related to vitamin A that can actually pass further into the dermis, including into the blood vessels, which then could have systemic effects. In fact, tretinoin (also known as retinoic acid or Retin-A) is often used in the treatment of dermatological conditions, from photoaging to acne and psoriasis (7).

Given the original impetus for writing this article, I couldn't help but ask the team of dermatologists if it was possible that a product applied topically by a spa technician could cleanse my liver. All replied with an emphatic no. Detmar in particular commented, "In the concentrations available to spas, it is not really possible for a compound to get to your liver to 'cleanse' it. I think that state-

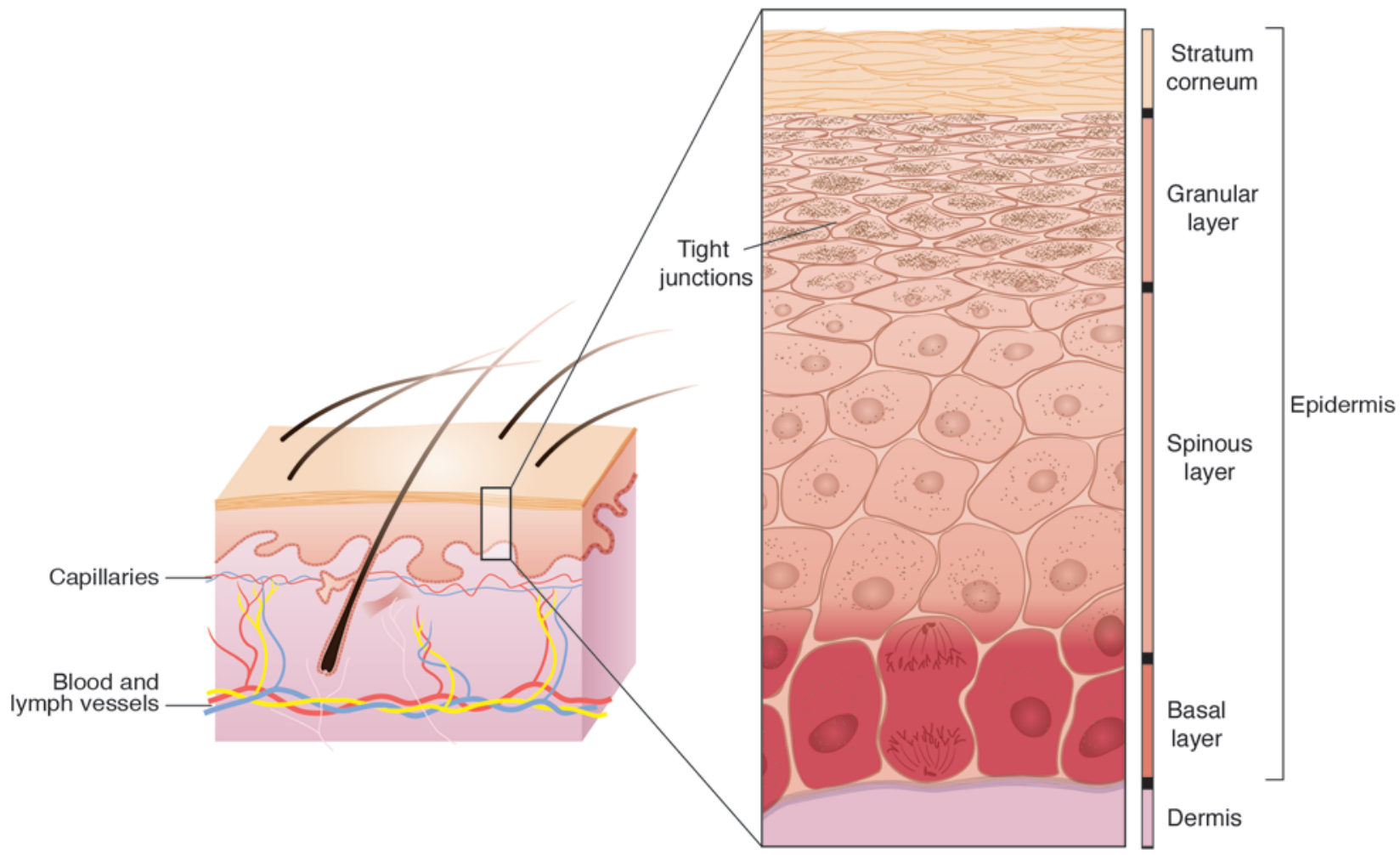

Figure 2

Human skin is composed of two primary layers, the epidermis, containing the outermost layers, and the dermis, with the connective tissue, hair follicles, and blood and lymphatic vessels. 


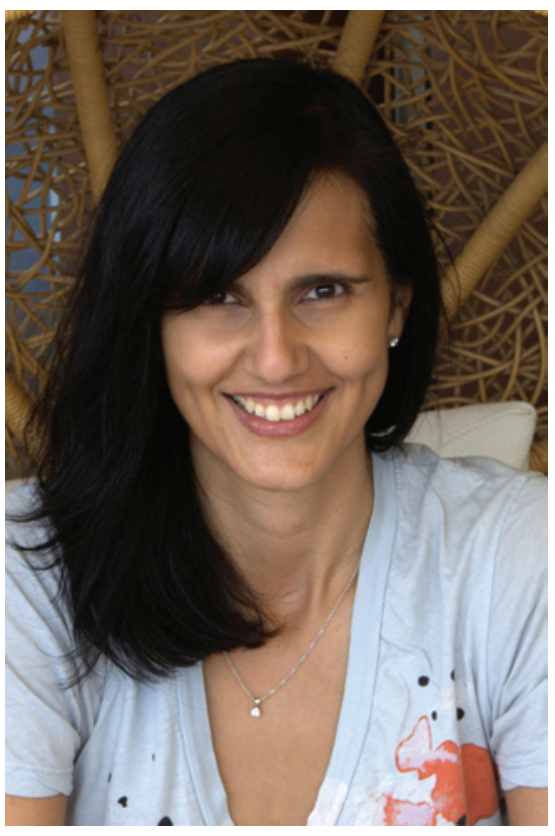

Figure 3

The author, described as having both slightly sun-damaged and dehydrated skin, and also the perfectly normal skin of a 20 -something year old. No comment on actual age at time of writing.

ment belongs more to voodoo than to reality." Two exceptions were mentioned: steroids applied topically can enter the circulation and can suppress the adrenal-pituitary axis, and carbon tetrachloride can also penetrate - but that compound is toxic to the liver when put on the skin and would be an unlikely component to a spa treatment. So, essentially, I could end the article here: it is sadly impossible to cleanse the liver at a spa, because as Stanley mentioned to me, "It is safe to assume that anything being applied in a spa is unlikely to penetrate far enough to enter the circulation and hence reach the liver, because if they were applying things that entered the circulation, they would be considered to be drugs and that would have to be regulated by the FDA."

We turned the conversation away from the liver and back to the face; I asked them if there would ever be a case in which there would be a medical benefit to getting a facial. The primary clinician in the group, Mudgil, said, "I never recommend this to my patients. Whenever you have darker pigmentation, and the facialist squeezes out whatever is there - pimples and the like, they can do a lot more harm than good, in the sense that you can end up with hyperpigmentation which can take months to go away." Cotsarelis added that there is no benefit for people with normal skin which is the greater part of the population. The only one to disagree was Stanley, saying that a facial can achieve desquamation of dead cells. "The stratum corneum flakes, and you could take off the very superficial layer - if there is a little scaling, a facial can remove that. And there are certain types of facials that a dermatologist could do - with glycolic acid and that can cause inflammation, and with inflammation you get a little temporary edema, and with edema in your face, you look better because you see a transient improvement in fine wrinkling."

I quoted to these experts the online estheticians' claims about the major health benefits of regular facials: regulation of the immune system, detoxification, reduction in fluid buildup, stimulation of lymphatic drainage, exfoliation, and stress relief. Stanley said they got it partly right, "I can certainly see how getting a facial could aid in stress relief - and I guess you could say that relaxation modulates the immune system, but a facial is not going to have a direct effect on immune cells. And note that what we said before is in direct opposition to what they're saying: facials can cause inflammation and then edema, and they're saying that a facial causes less fluid in the skin. If you have less fluid in your skin, you look dry."

On the point of fluid build up and lymphatic drainage, two of the academics saw different sides. "I don't actually understand what is meant by 'reduction in fluid buildup' as pertains to the skin unless they mean edema from heart failure - but your kidneys do that for you, not your skin," said Cotsarelis. "And when do you even have lymphatic drainage problems? If you do, you're certainly not going to get a facial to solve them. A normal person does not have lymphatic problems on their face." In contrast, Detmar says there is a constant flow of lymphatic fluid in our skin. When fluid leaks from blood vessels, it is taken up by the network of lymphatics: that is the normal flushing system in our bodies. During aging, especially if you have sun-damaged skin, then lymphatic function deteriorates and you have fewer lymphatic vessels $(8,9)$. He commented, "You might be able to make a case that you could reduce fluid buildup by having a facial to encourage drainage when your skin has fewer lymphatics. So promoting lymphatic flow can have benefits. Whether or not this is achieved with a facial is a different story."

\section{The scientific study}

I (Figure 3) decided to conduct my own scientific study wherein I asked Dr. Mudgil to assess my skin before and after a facial (though I did not tell him what I was going to have done to my face) to determine whether there was any noticeable difference. Mudgil noted, "You have the benefit of having a fair bit of pigment in your skin, so your skin is very youthful - you have the skin of a 20-something year old, even though I'd wager that you are more likely to be in your mid to late 30s. It can be very hard to tell with darker skinned Asians or Africans how old they are based on their skin. Your skin is really perfectly normal, so I'm not sure I'm going to be able to tell a difference at all in subsequent visits of whether you've had anything done."

On the advice of several beauty-conscious friends, I chose a medispa run by a dermatologist in downtown Manhattan for a basic facial. My facialist (one of the estheticians who did not want to be named) claimed I had "a little bit of congestion in your $\mathrm{T}$ zone, and you actually seem a bit dehydrated. I would say you have combination skin where it is oily in your $\mathrm{T}$ zone and dry everywhere else. Your nose and cheeks also have some sun damage." She recommended that I start using an exfoliator with beads or enzymes to help "brighten the skin and bring new cells up." She also advised me to use an eye cream, as "you're a little dry in that area. You have no major wrinkles, but you really want to keep that area hydrated in order to prevent them from appearing."

I went back to see Dr. Mudgil the day after having the facial to see whether he could ascertain what, if anything I had done to my face, but he noted that whatever I had done was subtle. Given that I had some subtle erythema between my brows, he postulated that I did something that was exfoliative - something perhaps like a chemical peel. When I revealed that I had just had a basic facial - and told him my esthetician's evaluation of my skin (combination skin), he 
agreed, but said, "Essentially everyone has combination skin, and I would say you're on the very low end of that spectrum - your skin is extremely normal all over. The area of the face with the greatest density of sebaceous glands is in your T zone - your nose probably has the most." When I asked him whether he noted any sun damage on my nose and cheeks, he disagreed with the esthetician's assessment, saying, "Your skin is amongst the least sun-damaged skin of any of my patients in your age range. People with more pigment in their skin tend not to harbor as much sun damage." However, this pigmented skin has limits to its benefits. Mudgil mentioned, "as much as your ethnicity can be a sun protectant, you are going to be plagued by your genetics. Indians tend to have deeper-set eyes and more discoloration under their eyes." So, alas, the esthetician's tip to keep my under-eye area better hydrated may be in vain.

My visit to Dr. Mudgil ended with some tips: don't get facials, as they can do more harm than good. He recommended a daily facial moisturizer with an SPF 15 in it, even if it is raining or snowing outside. He also added that I should wash my face twice a day with mild multipurpose acne wash - even if I don't have acne. Then after I reach a certain threshold of "wisdom," to use a retinoid at night.

\section{Beauty is only skin deep (but can it deepen with product application?)}

I decided to further query the team of dermatologists about skincare products and how best to maintain youthful skin, this time with a focus on topical, over-the-counter products. Each one of our experts mentioned that the single most important thing to remember when trying to maintain youthful skin is the daily application of sunscreen - especially those with titanium dioxide or zinc oxide, which are actual physical blockers of the sun. Stanley specifically commented, "Sun protection is the single most important thing to ensure your skin looks good for a long time. All the other things you could do to your skin are so minor compared to sun protection - and it's not just sunscreen: clothing and hats and just not baking in the sun.”

What about other products, like cleansers? On this point, Cotsarelis pointed out that people used to use soap that advertised itself as being $99.44 \%$ pure. He noted, "it is amazing how many people you see in clinical practice who have dried out skin or itchy flaky skin, especially in the wintertime, and it is solely due to their soap. Americans tend to over bathe, and those that shower twice a day - they're drying themselves out. The point of soap is to remove oils, but the skin needs some oil and moisture. If everyone used moisturized soap, we'd really cut down on the number of dermatology visits." He also told me what he learned during his medical training from Albert Kligman, the renowned University of Pennsylvania dermatologist who discovered tretinoin (Retin-A), and what he told all his patients: "You should use Vaseline at night to take off your makeup. Use a tissue to wipe of the excess, and that creates a barrier and keeps the skin moisturized."

When I asked the dermatologists whether there should be a difference between the products you apply directly under your eyes and to the rest of your face, Stanley said that the skin under your eyes is so thin that you would have a much more visible reaction to an irritant in that part of your face, so it is reasonable to use a product that is moisturizing without other components, while Cotsarelis noted, "Vaseline works there too."

But would Vaseline work to prevent the appearance of aging? I moved on to ask the panel whether there should be a difference between the skin-care products used before and after age 50, given the enormous cosmetic marketing efforts aimed at older women. "I think this is not remarkably logical," said Detmar. "Some people have the appearance of being 50 when they are 30 . Some don't appear 50 until they are 60. It is the skin type that is much more relevant than your age. If you have dry skin, there are specific products for you, whether you're 35 or 55." Mudgil agreed, saying, "The skin is different in an older person, but the recommendations are otherwise exactly the same." Cotsarelis added that the major difference between young and old skin is the extent of sun exposure: "That can lead to loss of collagen and elastin, which usually keeps your skin taut. And there are also the effects of gravity. So sure, if you have saggy, wrinkly skin, or brown spots, you would see a lot more benefit from lasers and peels and from topically applied compounds."

Is there any difference between the skin-care products created for men versus women? Detmar replied, "Yours are more expensive. Other than that, sure, there are hormonal differences which could dictate use of certain components." But that brings up a good point: should we be spending $\$ 150$ for a one-ounce pot of Crème de la Mer instead of $\$ 9$ on a six-ounce bottle of Oil of Olay? Does the brand or the cost really matter? "There is a psychological effect from spending more," noted Stanley. "One of my female relatives buys according to the advertisements - she says the products work better and sometimes if it costs more, she likes it even better. Even if I tell her the items on the label aren't making it into her hair or her skin, she doesn't care. So much of skin and hair care is based on psychology." Costarelis did have one addition to this argument, though. He said that if a product comes from a big company, the chance of having an adverse reaction is much smaller and the product is more likely to work as advertised, as the bigger companies tend to do more extensive testing before launching a product in the market. He said, "The marketing branch of these companies is the one doing studies on what is most effectively going to appeal to buyers - the marketing can be really slick and can twist things in ways that aren't completely dishonest, but are fairly far from what the scientists actually showed." Regardless, he still recommends buying products from a brand name that you know and have prior experience with. He went on to say, "When you see some of the herbal tinctures and new brands pop up, you have no idea what is actually in the products. Each batch is also probably quite different."

So what about products that are branded as natural or organicare they more effective or safer to apply to the skin? "I think you'd be deceiving yourself a little bit there by thinking that just because it is natural, it is going to be more effective. There are caustic acids in lemons," noted Cotsarelis. Stanley went on to note that juice from limes can cause a photodermatitis that is severe in people that have gin and tonics: "You see it all the time in people drinking those by the pool. It can be a severe pigmentation problem and can cause a bad reaction. And that is a natural product. Natural doesn't mean it's not going to hurt you if you put it on your skin. Poison ivy is a natural product, and you don't rub that on your skin."

Last but not least, the ultimate goal for aging females like me: I asked the panel whether there are any topical treatments to reduce or prevent the appearance of fine lines and wrinkles, and unsurprisingly, it all came back to retinoids. Mudgil said, "A retinoid is very important to use, and there are formulations that are not as drying that I use for my acne patients or even for my Botox patients that 
want to maintain youthful skin." Detmar noted the oldest trick the cosmetic industry has: "You can very easily reduce the appearance of wrinkles with the use of a moisturizer. Most of the cosmetic treatments are variations on moisturizers; they immediately reduce the appearance of fine lines by $15 \%-20 \%$. Preventing their appearance is a different issue. The daily use of retinoids can prevent the appearance of wrinkles; they penetrate into the skin, can work on the extracellular matrix - the collagen and elastin fibers."
Final lessons: use sunscreen, Vaseline, and retinoids; don't bother with facials; don't rub poison ivy and citrus juices on your skin; and don't be seduced by fancy packaging and high prices. Easy enough!

Address correspondence to: Ushma Neill, Journal of Clinical Investigation, 15 Research Drive, Ann Arbor, Michigan 48103, USA. Phone: 734.222.6050; Fax: 734.222.6058; E-mail: editors@the-jci.org.
1. Skin Care Industry News. News and Information about the Skin Care Industry. Skin Care Industry Web site. http://skincareindustrynews.com. Accessed December 16, 2011.

2. ISPA Releases 2009 U.S. Spa Industry Statistics. Hospitality Net Web site. http://www.hospitalitynet.org/news/154000320/4042313.search?que $r y=s p a+i n d u s t r y+$ statistics. Updated July 2, 2009. Accessed December 16, 2011

3. Why You Should Get A Facial ASAP. Askanesthetician's Blog Web site. http://askanesthetician. wordpress.com/2010/05/12/why-you-should-get- a-facial-asap. Updated May 12, 2010. Accessed December 16, 2011.

4. Moyer CA, Seefeldt L, Mann ES, Jackley LM. Does massage therapy reduce cortisol? A comprehensive quantitative review. J Bodyw Mov Ther. 2011;15(1):3-14.

5. Rapaport MH, Schettler P, Bresee C. A preliminary study of the effects of a single session of Swedish massage on hypothalamic-pituitary-adrenal and immune function in normal individuals. J Altern Complement Med. 2010;16(10):1079-1088.

6. Bello D, White-Traut R, Schwertz D, Pournajafi-
Nazarloo H, Carter CS. An exploratory study of neurohormonal responses of healthy men to massage. J Altern Complement Med. 2008;14(4):387-394.

7. Futoryan T, Gilchrest BA. Retinoids and the skin. Nutr Rev. 1994;52(9):299-310.

8. Kajiya K, Detmar M. An important role of lymphatic vessels in the control of UVB-induced edema formation and inflammation. $J$ Invest Dermatol. 2006;126(4):919-921.

9. Kajiya K, Kunstfeld R, Detmar M, Chung JH. Reduction of lymphatic vessels in photodamaged human skin. J Dermatol Sci. 2007;47(3):241-243. 